\title{
Adenoid cystic carcinoma of the palpebral lobe of the lacrimal gland - case report and literature review
}

Ana Filipa Duarte, Diogo Alpuim Costa, Nuno Caçador, Ana Magriço Boavida, Ana M Afonso, Miguel Vilares \& Martin Devoto

To cite this article: Ana Filipa Duarte, Diogo Alpuim Costa, Nuno Caçador, Ana Magriço Boavida, Ana M Afonso, Miguel Vilares \& Martin Devoto (2021): Adenoid cystic carcinoma of the palpebral lobe of the lacrimal gland - case report and literature review, Orbit, DOI: 10.1080/01676830.2021.1901293

To link to this article: https://doi.org/10.1080/01676830.2021.1901293

View supplementary material $\sqsubset \nearrow$

Published online: 22 Mar 2021.

Submit your article to this journal $\llbracket$

View related articles $\asymp$

View Crossmark data $₫$ 


\title{
Adenoid cystic carcinoma of the palpebral lobe of the lacrimal gland - case report and literature review
}

\author{
Ana Filipa Duarte ${ }^{a}$, Diogo Alpuim Costa ${ }^{b}$, Nuno Caçador ${ }^{c}$, Ana Magriço Boavidaa ${ }^{a}$ Ana M Afonso ${ }^{d}$, Miguel Vilarese, \\ and Martin Devoto ${ }^{f}$ \\ aDepartment of Ophthalmology, Hospital CUF Descobertas, Lisbon, Portugal; 'Department of Hematology and Oncology, CUF Oncologia, \\ Lisbon, Portugal; 'Department of Radiology, Hospital CUF Descobertas, Lisbon, Portugal; 'Department of Pathology, Hospital CUF Descobertas, \\ Lisbon, Portugal; 'Department of Head and Neck Surgery, Instituto Português de Oncologia de Lisboa Francisco Gentil E.P.E. (IPOL-FG), Lisbon, \\ Portugal; ' Department of Ophthalmology, Clinica Consultores Oftalmológicos, Buenos Aires, Argentina
}

\begin{abstract}
Epithelial tumors of the lacrimal gland are rare and usually develop in the orbital lobe. We report the exceedingly rare occurrence of a primary adenoid cystic carcinoma in the palpebral lobe of the lacrimal gland. A 26-year-old female was referred for evaluation of a gradually enlarging mass in the lateral upper eyelid, previously diagnosed as a chalazion. Computed tomography revealed a heterogeneous round lesion anterior to the orbital rim. Excisional biopsy was compatible with an adenoid cystic carcinoma. After excluding distant metastasis, and as the patient refused adjuvant radiotherapy, a second surgical procedure, with wide local excision, was indicated. Follow-up showed no recurrence. This case highlights the importance of performing a thorough clinical examination when diagnosing any lateral upper eyelid mass. A high index of suspicion for malignant tumors of the lacrimal gland should always be maintained, and a complete excision with histological analysis should be preferred whenever possible.
\end{abstract}

\section{ARTICLE HISTORY}

Received 6 October 2020 Accepted 2 March 2021

\section{KEYWORDS}

Adenoid cystic carcinoma; lacrimal gland; lacrimal gland tumors; palpebral lobe

\section{Introduction}

Lacrimal gland (LG) tumors are rare, corresponding to 3-18\% of all orbital lesions. ${ }^{1}$ Primary epithelial tumors account for $20-45 \%$ of all neoplasms of the LG, half of which are malignant. ${ }^{1,2}$ In this latter subgroup, adenoid cystic carcinoma (ACC) accounts for approximately $60 \%$ of cases ${ }^{2}$ and generally arises from the orbital lobe. ACC of the LG presents a bimodal age distribution, occurring most often in middle age, with a second peak in the first decade of life. ${ }^{2}$ Usually, patients describe the progression of symptoms over less than one year, often less than six months. ${ }^{3}$ Primary malignant epithelial tumors originating from the palpebral lobe of the LG are exceedingly rare, with only three cases described in the literature. ${ }^{4}$ Among these, only one corresponded to an ACC. ${ }^{4}$

We report a case of ACC arising in the palpebral lobe of the LG in a 26-year-old female patient, initially misdiagnosed as a chalazion, emphasizing the importance of a careful preoperative examination of all eyelid lesions.

\section{Case report}

A 26-year-old black female was referred for evaluation of a right upper eyelid mass with progressive growth in the last eight months. A previous surgical excision had been attempted six months earlier, with no improvement.

The patient denied pain, paresthesia, diplopia or other associated ophthalmological symptoms. On clinical examination, a painless, non-tender, mobile mass of 1 to $1.5-\mathrm{cm}$ was palpated laterally on the upper eyelid (Figure 1A). A prolapsed palpebral lobe of the LG was visible after eyelid eversion, with no identifiable mass. Visual acuity was $20 / 20$ on both eyes, ocular motility was normal, and no proptosis or globe displacement was observed. Computerized tomography showed a round well-circumscribed heterogeneous lesion, anterior to the orbital rim, with no associated bone erosion or globe deformation (Figure 1B). An excisional biopsy was performed through an upper eyelid skin-crease approach. An exceedingly thin levator aponeurosis was incised, and an encapsulated mass removed with the capsule intact. Histopathological examination revealed a $16 \times 10$ × $8 \mathrm{~mm}$ low-grade ACC with a cribriform pattern and no vascular or perineural spread (Figure $2 \mathrm{~A}-\mathrm{C}$ ). Radiological staging excluded distant metastases, and orbital and brain magnetic resonance images did not show any signs of

CONTACT Ana Filipa Duarte ana.f.duarte@cuf.pt Departamento de Oftalmologia, Hospital Cuf Descobertas, Rua Mário Botas, Lisboa 1998-018, Portugal. (4) Supplemental data for this article can be accessed on the publisher's webiste.

(c) 2021 Taylor \& Francis Group, LLC 


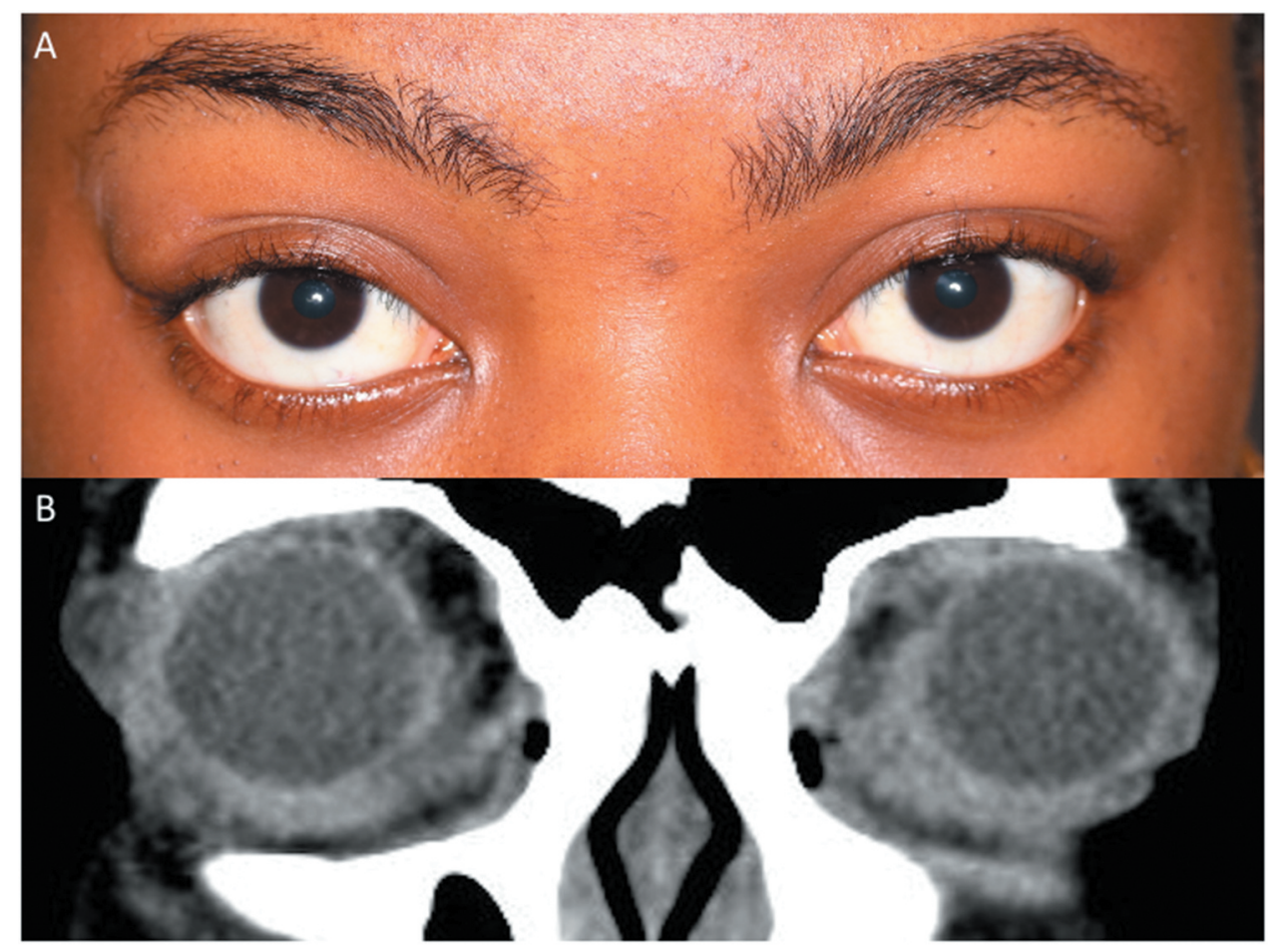

Figure 1. Initial presentation. (A) Well-defined $10 \times 15-\mathrm{mm}$ mobile mass in the temporal area of the right upper eyelid. (B) Orbital computed tomography showing a round heterogeneous soft tissue lesion in the superotemporal quadrant of the right orbit.

perineural spread or suspicious soft tissue changes. After a multidisciplinary tumor board, adjuvant radiotherapy was indicated; however, it was refused as the patient needed to return to her native country (Angola). As an alternative, a second surgical procedure for wide local excision followed by close surveillance was planned. Two weeks after the first surgery, the remaining palpebral lobe of the lacrimal gland was removed along with adjacent tissues. No residual tumor was detected. The patient has been followed up regularly with clinical examination and magnetic resonance imaging, and three years after the second procedure, no signs of recurrence were noticed (Figure 3). In the last evaluation, visual acuity, intraocular pressures, globe position, and motility were unremarkable, and only a $1 \mathrm{~mm}$ right ptosis and mild dry eye symptoms, consistent with a Schirmer test (without anesthetic) of $4 \mathrm{~mm}$ on the right and $16 \mathrm{~mm}$ on the left, were observed. Regular lubrication has been recommended for the control of dry eye symptoms.

\section{Discussion}

The LG is composed of two portions: an orbital (deep) and a palpebral (superficial) lobe, separated by the lateral horn of the levator muscle aponeurosis. ${ }^{5}$ The presence of cells of different histological origins allows the development of several distinct types of neoplasms, usually divided into epithelial, lymphoid and mesenchymal. ${ }^{6}$ To the best of our knowledge, only 75 primary tumors of the palpebral lobe were reported in the literature ${ }^{4,7-20}$ (Supplementary Table 1). Among these, 71 had an epithelial origin, in most cases (95.8\%) pleomorphic adenomas (PA), ${ }^{4,7-20}$ the remaining corresponding to one carcinoma in-pleomorphic adenoma, one carcinoma ex-pleomorphic adenoma, and only one case was compatible with an ACC. ${ }^{4}$

In 1996, Vangveeravong S. et al. reported the clinical features and treatment outcomes of six tumors of the palpebral lobe of the LG comprising three benign and three malignant lesions, including one ACC. ${ }^{4}$ All tumors were initially described as a progressively growing palpable mass or swelling in the lateral upper eyelid, with no other signs such as proptosis, globe displacement, motility or visual impairment. These nonspecific clinical features include a wide range of differential diagnoses, such as chalazion, dermoid or sebaceous cysts, as well as epithelial and non-epithelial lesions of the lacrimal gland, including dacryops, dacryoadenitis or lymphoma. In addition, ectopic lacrimal gland tissue may present in the upper or lower eyelid as masses, ${ }^{21}$ where benign and malignant lesions can develop. In our patient, although the lesion could be similar in shape and topography to a chalazion, careful palpation allowed its location outside the tarsal 


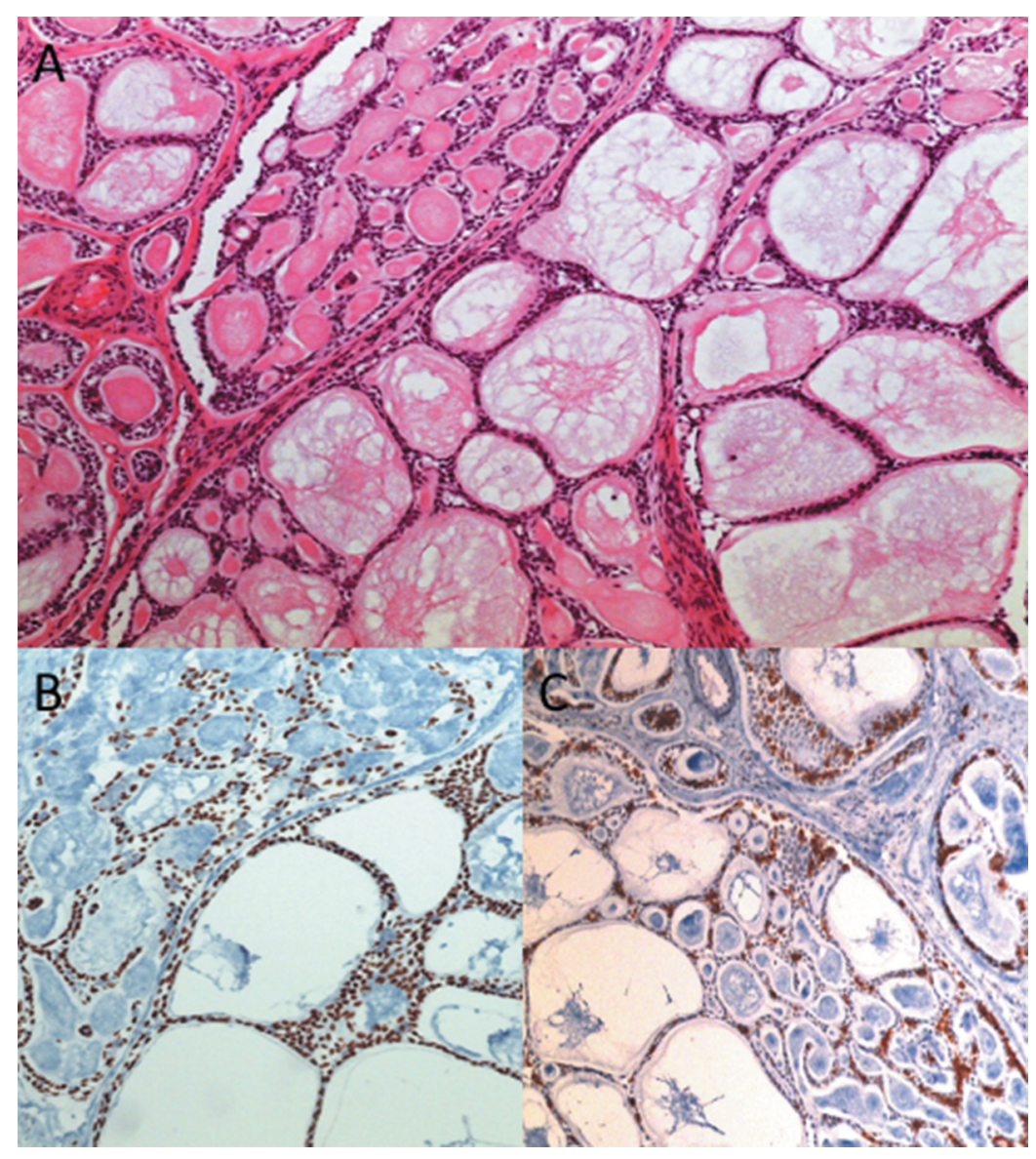

Figure 2. (A) Histopathology, H\&E 100x, of the eyelid lesion showing an epithelial neoplasm with a cribriform pattern. In immunohistochemistry, Kit (CD117) typically marks epithelial (inner) cells (B) and p63 marks myoepithelial (peripheral) cells (C).

plate. Intraoperatively, an origin from the palpebral lobe was assumed given its position immediately below a thin and locally atrophic levator aponeurosis.

We agree that any palpable and well-circumscribed lesion with an anterior location outside the orbital rim, confirmed by imaging, should be initially managed with complete excision. Firstly, because when located in the superotemporal region of the upper eyelid, there is a not negligible probability of corresponding to a PA, with a significant risk of recurrence (and possible malignant transformation) if incompletely extirpated ${ }^{22-24}$; and secondly, also highlighted by Vangveeravong et al., there is no reason to perform a partial resection, or even incisional biopsy, of a mass that can be easily excised. ${ }^{4}$

We can find some similarities between our patient and the 41-year-old male described by Vangveeravong et al. ${ }^{4}$, and the most commonly described presentation of orbital lobe ACC: both presented less than one year of symptom progression and followed the classic bimodal age distribution. The distinguishing features were the absence of pain, paresthesia or bone changes, which are more suggestive of malignancy yet also inconsistently present in orbital lobe tumors. ${ }^{25}$ The more anterior location of these palpebral lobe lesions, with no contact with the orbital rim, may also justify the absence of earlier bone changes. Two cases of palpebral lobe ACC are, however, insufficient to draw any conclusions about its specific behavior in this anatomic area. We believe that there might be an under-reporting of lesions primarily arising from the palpebral lobe. Most of the case series found in our literature review lack the specification of which lobe the tumors originated from, categorizing them according to size and/or stage (American Joint Committee on Cancer staging system). We can point out three possible explanations for this: 1) Considering that most of these studies are retrospective, the authors may use the generic term of LG tumor as this is the description shown in clinical files, pathology and imaging reports; 2) The authors do not value such distinction assuming that it does not interfere with the management or prognosis; 3 ) Malignant tumors arising from the palpebral lobe are in fact, exceedingly rare. We 


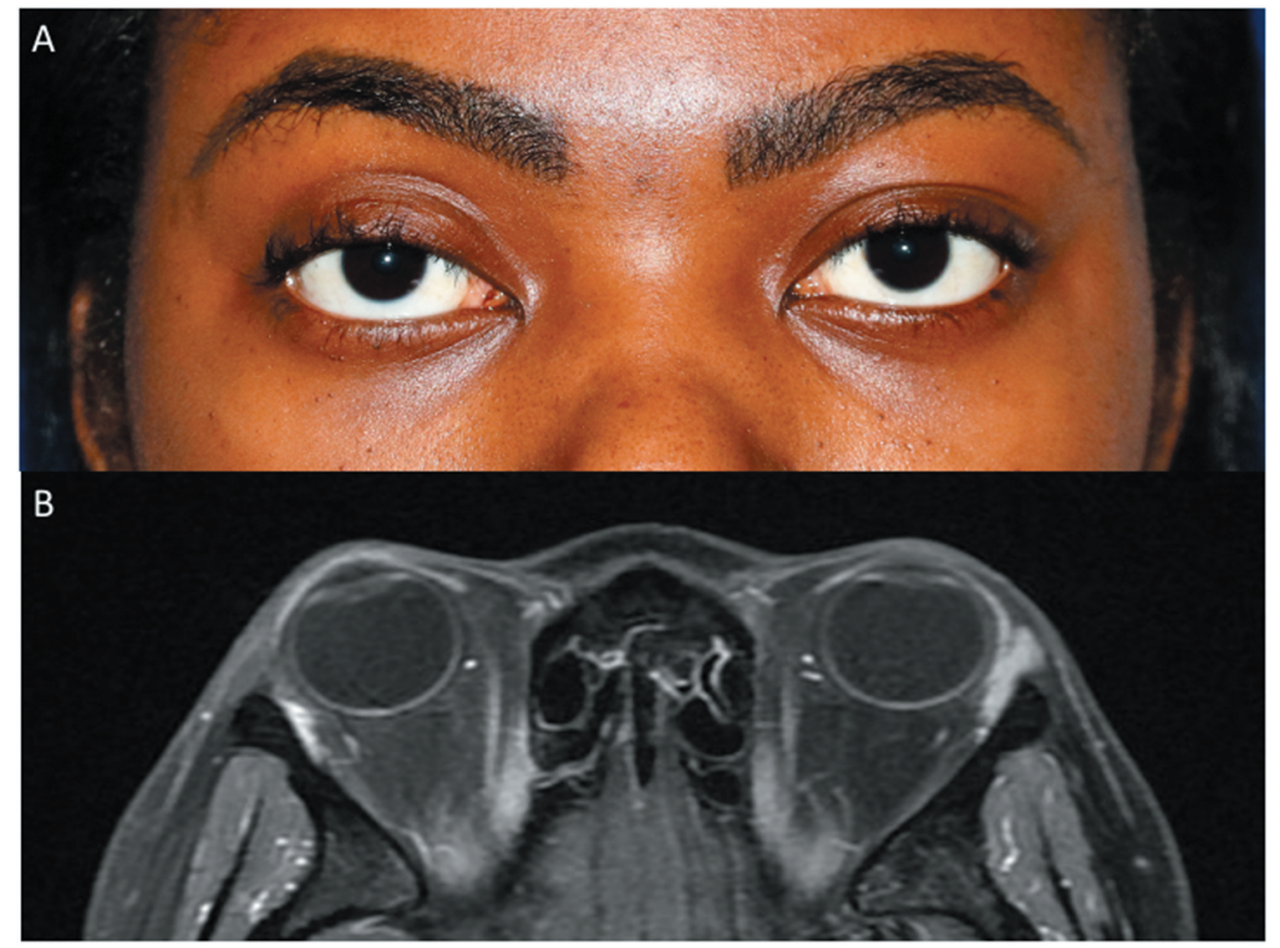

Figure 3. (A) Clinical appearance three years after surgery shows only a mild right upper eyelid ptosis. (B) Axial MRI T1 discloses a discrete signal reinforcement in the external contour of the surgical area.

found only one retrospective study by Shields JA et al. specifying whether unilateral lacrimal gland lesions showed an involvement of the palpebral and/or the orbital lobe on magnetic resonance imaging. ${ }^{26}$ In their series, only chronic dacryoadenitis showed a palpebral lobe extension. Therefore, we highlight the need to present this distinction whenever possible, so that differences in the behavior and the impact of treatments now used in orbital lobe tumors might be evaluated. Few other cases of non-epithelial tumors originating from the palpebral lobe were identified (Supplementary Table 1) and included a neurofibroma in a 62-year-old man, ${ }^{27}$ a metastatic renal cell carcinoma in a 59 -year-old man, ${ }^{28}$ an 18-month-old child with a sialoblastoma-like tumor with a sarcomatoid myoepithelial component, ${ }^{29}$ and a 22-year-old woman with an epithelioid hemangioendothelioma. ${ }^{30}$ All these reports highlight the unusual occurrence of each type of lesion in this anatomic location and become arguments of how a high index of suspicion is needed for any mass in this area.

The aggressiveness and high mortality rates of lacrimal gland ACC are well known. Although there have been some controversies, the paradigm of treatment of this aggressive tumor has shifted over the past decades. Contemporary approaches now favor an eye-sparing multidisciplinary management whenever possible, complemented with adjuvant treatment (radiotherapy and eventually chemotherapy). ${ }^{31-35}$ The development of new radiotherapy modalities such as intensity-modulated radiotherapy and the intensity-modulated proton therapy, with fewer side effects, have markedly reduced the post-treatment burden of previous radiation delivery techniques. $32,35,36$ Neoadjuvant intra-arterial chemotherapy has also been used with promising results, ${ }^{37}$ and recent search for cancer-associated mutations and potential molecular targets has added important steps in the long and challenging journey of treating advanced forms and metastatic disease. ${ }^{38,39}$

Regarding our patient, the preference for a wide surgical excision as an alternative to adjuvant radiotherapy was made considering the patient's desire to return to her native country. In fact, despite all the advances in ACC therapy, extensive local resection without further treatments has been an accepted procedure in specific circumscribed lesions. ${ }^{3,40}$ That indication was considered beneficial in this particular case. All the prognostic factors for local recurrence and survival were considered, namely the lesion size (T1N0M0 according to the American Joint Committee on Cancer classification, $8^{\text {th }}$ edition), the histologic type (non-basaloid) and the absence of perineural invasion. ${ }^{25,32,40}$ Importantly, the decision also depended on the patient's commitment to maintaining a strict clinical and radiologic surveillance. 
In summary, we report the exceedingly rare occurrence of an ACC of the palpebral lobe of the LG, illustrating the importance of maintaining a high level of suspicion for any temporally located upper eyelid mass. A thorough ophthalmic examination with palpation and eyelid eversion is crucial and may allow the immediate diagnosis of benign and more common conditions such as dermoid/epidermoid cysts, chalazion or dacryops. Well delimited lesions should be removed with an en bloc resection technique whenever possible, with histology, clinical and radiological staging guiding the treatment plan. Also, some attention should be paid in future studies regarding the specific location of a LG tumor. More substantiated data may open a new paradigm in the management of lesions arising from the palpebral lobe.

\section{Authorship}

All authors attest that they meet the current ICMJE criteria for Authorship.

\section{Disclosure statement}

The following authors have no financial disclosures: Ana F Duarte, Diogo Alpuim Costa, Nuno Caçador, Ana Magriço, Ana M Afonso, Miguel Vilares, Martin Devoto.

\section{Patient consent}

The report is in accordance with the Helsinki Declaration as revised in 2013, and written consent to publish identifying information, including photographs, was obtained from the patient. Photographs were taken with proper authorization.

\section{References}

1. Gunduz AK, Yesiltas YS, Shields CL. Overview of benign and malignant lacrimal gland tumors. Curr Opin Ophthalmol. 2018;29(5):458-468. doi:10.1097/ ICU.0000000000000515.

2. Shields JA, Shields CL, Epstein JA, Scartozzi R, Eagle RC Jr. Review: primary epithelial malignancies of the lacrimal gland: the 2003 Ramon L. Font lecture. Ophthalmic Plast Reconstr Surg. 2004;20(1):10-21. doi:10.1097/01. IOP.0000103003.87842.BB.

3. Dutton JJFS, Proia AD. Diagnostic Atlas of Orbital Diseases. Philadelphia: W.B. Saunders; 2000.

4. Vangveeravong S, Katz SE, Rootman J, White V. Tumors arising in the palpebral lobe of the lacrimal gland. Ophthalmology. 1996;103(10):1606-1612. doi:10.1016/ S0161-6420(96)30456-9.

5. Dutton JJWT. Atlas of Clinical and Surgical Orbital Anatomy. 2nd ed. Philadelphia, PA: Elsevier Saunders; 2011.

6. von Holstein SL, Rasmussen PK, Heegaard S. Tumors of the lacrimal gland. Semin Diagn Pathol. 2016;33 (3):156-163. doi:10.1053/j.semdp.2015.10.002.
7. Murphy MB, Rodrigues MM. Benign mixed tumor of the (palpebral) lacrimal gland presenting as a nodular eyelid lesion. Am J Ophthalmol. 1974;77(1):108-111. doi:10.1016/0002-9394(74)90615-1.

8. Wright JE, Stewart WB, Krohel GB. Clinical presentation and management of lacrimal gland tumours. $\mathrm{Br}$ J Ophthalmol. 1979;63(9):600-606. doi:10.1136/bjo.63. 9.600 .

9. Auran J, Jakobiec FA, Krebs W. Benign mixed tumor of the palpebral lobe of the lacrimal gland. Clinical diagnosis and appropriate surgical management. Ophthalmology. 1988;95(1):90-99. doi:10.1016/S01616420(88)33223-9.

10. Parks SL, Glover AT. Benign mixed tumors arising in the palpebral lobe of the lacrimal gland. Ophthalmology. 1990;97(4):526-530. doi:10.1016/S0161-6420(90)32572-1.

11. Yamada T, Kato T, Hayasaka S, Hayasaka Y, Kadoi C. Benign pleomorphic adenoma arising from the palpebral lobe of the lacrimal gland associated with elevated intraocular pressure. Ophthalmologica. 1999;213 (4):269-272. doi:10.1159/000027434.

12. Hsu H. Posttraumatic benign pleomorphic adenoma of the lacrimal gland. Ophthalmologica. 2001;215 (215):235-237. doi:10.1159/000050865.

13. Cunniffe G, Chang BY, Kennedy S, Moriarty P. Beware the empty curette! Orbit. 2002;21(2):177-180. doi:10.1076/orbi.21.2.177.7191.

14. Marshall AF, White DR, Shockley WW. Pleomorphic adenoma in the palpebral lobe of the lacrimal gland. Otolaryngol Head Neck Surg. 2005;132(1):141-143. doi:10.1016/j.otohns.2004.03.021.

15. Ramlee N, Ramli N, Tajudin LS. Pleomorphic adenoma in the palpebral lobe of the lacrimal gland misdiagnosed as chalazion. Orbit. 2007;26(2):137-139. doi:10.1080/ 01676830600985882.

16. Porter N, Sandhu A, O'Connell TB, Selva D, Leibovitch I. Pleomorphic adenoma of the palpebral lobe of the lacrimal gland. Otolaryngol Head Neck Surg. 2007;136(2):328-329. doi:10.1016/j.otohns.2006.06.1245.

17. Yan J, Chen J, Shen T. Pleomorphic adenoma arising from the palpebral lobe of the lacrimal gland in a patient with thyroid-associated ophthalmopathy. J Craniofac Surg. 2015;26(2):e187-8. doi:10.1097/ SCS.0000000000001453.

18. Watanabe A, Andrew $\mathrm{NH}$, Ueda K, Kinoshita S, Katori N, Reid $\mathrm{M}$, et al. Clinico-radiological features of primary lacrimal gland pleomorphic adenoma: an analysis of 37 cases. Jpn J Ophthalmol. 2016;60(4):286-293. doi:10.1007/s10384-016-0451-3.

19. Sa Bs H, Warad VG. Pleomorphic adenoma of palpebral part of lacrimal gland: a rare case report. Albasar Int J Ophthalmol. 2017;4(4):31-33.

20. Vahdani K, Rose GE. Palpebral pleomorphic adenomas of the lacrimal gland. Ophthalmic Plast Reconstr Surg. 2021 Mar-Apr 01;37(2):125-128. doi: 10.1097/ IOP.0000000000001682.

21. Nagendran S, Alsamnan M, Strianese D, Malhotra R. Ectopic lacrimal gland tissue: a systematic review. Ophthalmic Plast Reconstr Surg. 2020;36(6):540-544. doi:10.1097/IOP.0000000000001621.

22. Currie ZI, Rose GE. Long-term risk of recurrence after intact excision of pleomorphic adenomas of the lacrimal 
gland. Arch Ophthalmol. 2007;125(12):1643-1646. doi:10.1001/archopht.125.12.1643.

23. Rose GE. To crash or not to crash? Probability in the management of benign lacrimal gland tumours. Eye (Lond). 2009;23(8):1625-1628. doi:10.1038/eye.2009.89.

24. Lai T, Prabhakaran VC, Malhotra R, Selva D. Pleomorphic adenoma of the lacrimal gland: is there a role for biopsy? Eye (Lond). 2009;23(1):2-6. doi:10.1038/eye.2008.16.

25. Proia AD, Ranjit-Reeves R, Woodward JA. Lacrimal gland tumors. Int Ophthalmol Clin. 2018;58 (2):197-235. doi:10.1097/IIO.0000000000000220.

26. Gunduz K, Shields CL, Gunalp I, Shields JA. Magnetic resonance imaging of unilateral lacrimal gland lesions. Graefes Arch Clin Exp Ophthalmol. 2003;241 (11):907-913. doi:10.1007/s00417-003-0748-z.

27. McDonald P, Jakobiec FA, Hornblass A, Iwamoto T. Benign peripheral nerve sheath tumors (neurofibromas) of the lacrimal gland. Ophthalmology. 1983;90 (12):1403-1413. doi:10.1016/S0161-6420(83)34365-7.

28. Shields JA, Shields CL, Eagle RC Jr., Singh AD, Armstrong T. Metastatic renal cell carcinoma to the palpebral lobe of the lacrimal gland. Ophthalmic Plast Reconstr Surg. 2001;17(3):191-194. doi:10.1097/ 00002341-200105000-00008.

29. Shet T, Ramadwar M, Sharma S, Laskar S, Arora B, Kurkure P. An eyelid sialoblastoma-like tumor with a sarcomatoid myoepithelial component. Pediatr Dev Pathol. 2007;10(4):309-314. doi:10.2350/06-07-0135.1.

30. Kiratli H, Tarlan B, Ruacan S. Epitheloid hemangioendothelioma of the palpebral lobe of the lacrimal gland. Orbit. 2013;32(2):120-123. doi:10.3109/ 01676830.2013 .764443 .

31. Esmaeli B, Yin VT, Hanna EY, Kies MS, William WN Jr., Bell D, et al. Eye-sparing multidisciplinary approach for the management of lacrimal gland carcinoma. Head Neck. 2016;38(8):1258-1262. doi:10.1002/hed.24433.

32. Ford JR, Rubin ML, Frank SJ, Ning J, Debnam JM, Bell D, et al. Prognostic factors for local recurrence and survival and impact of local treatments on survival in lacrimal gland carcinoma. Br J Ophthalmol. 2020. doi:10.1136/bjophthalmol-2020-316142.

33. Woo KI, Sagiv O, Han J, Frank SJ, Kim YD, Esmaeli B. Eye-preserving surgery Followed by adjuvant radiotherapy for lacrimal gland carcinoma: outcomes in 37 patients. Ophthalmic Plast Reconstr Surg. 2018;34 (6):570-574. doi:10.1097/IOP.0000000000001106.

34. Han J, Kim YD, Woo KI, Long-Term SD. Outcomes of eye-sparing surgery for adenoid cystic carcinoma of lacrimal gland. Ophthalmic Plast Reconstr Surg. 2018;34(1):74-78. doi:10.1097/IOP.0000000000000877.

35. Wolkow N, Jakobiec FA, Lee H, Sutula FC. Long-term outcomes of globe-preserving surgery with proton beam radiation for adenoid cystic carcinoma of the lacrimal gland. Am J Ophthalmol. 2018;195:43-62. doi:10.1016/j.ajo.2018.07.024.

36. Woo KI, Yeom A, Esmaeli B. Management of lacrimal gland carcinoma: lessons from the literature in the past 40 years. Ophthalmic Plast Reconstr Surg. 2016;32 (1):1-10. doi:10.1097/IOP.0000000000000531.

37. Zhang M, Fathy C, Breazzano MP, Hollar M, Intraarterial BB. Chemotherapy for lacrimal gland adenoid cystic carcinoma. Int Ophthalmol Clin. 2017;57 (1):143-152. doi:10.1097/IIO.0000000000000158.

38. Bell D, Sniegowski MC, Wani K, Prieto V, Esmaeli B. Mutational landscape of lacrimal gland carcinomas and implications for treatment. Head Neck. 2016;38(Suppl 1):E724-E9. doi:10.1002/hed.24078.

39. von Holstein SL, Fehr A, Persson M, Therkildsen MH, Prause JU, Heegaard S, et al. Adenoid cystic carcinoma of the lacrimal gland: MYB gene activation, genomic imbalances, and clinical characteristics. Ophthalmology. 2013;120 (10):2130-2138. doi:10.1016/j.ophtha.2013.03.030.

40. Ahmad SM, Esmaeli B, Williams M, Nguyen J, Fay A, Woog J, et al. American joint committee on cancer classification predicts outcome of patients with lacrimal gland adenoid cystic carcinoma. Ophthalmology. 2009;116 (6):1210-1215. doi:10.1016/j.ophtha.2008.12.049. 